\title{
تعليقات المعلم نحو ههارة الكابة لطلاب الفصل الحادي عشر بالمدرسة السلفية الثانوية الإسلامية تانجولانجين سيدوارجو
}

\author{
Abdurrasyid Akbar \\ abdurrosyidakbar96@gmail.com \\ UIN Sunan Ampel Surabaya \\ Hisbullah Huda \\ Hisbullahhuda@yahoo.com \\ UIN Sunan Ampel Surabaya
}

\begin{abstract}
The results of this study analyze "The impact of teacher comments on the writing skills of eleventh grade students at Salafiyah Islamic Middle School, Tangulangin Sidoarjo". The results of the questions answer the question about whether there is an influence of teacher comments on the writing skills of eleventh grade students of the Salafiyah Islamic Middle School of Tungulangin Sidwarjo. Researchers used qualitative and descriptive methods. As for the method of collecting data by means of observation, interviews and documents. This research is presented in the form of reports and descriptions, then arranged in the form of descriptive research results in the form of interactive analysis. The results of data analysis in this study are that teacher comments with scribbles in the form of written justification comments and reinforcement comments have a positive impact on improving students' writing skills as evidenced by student worksheets.
\end{abstract}

Keywords: teacher commentary; writing skills;

Abstrak: Artikel hasil penelitian ini menganalisis "Dampak komentar guru pada keterampilan menulis siswa kelas sebelas Sekolah Menengah Salafiyah Islam, Tangulangin Sidoarjo". Hasil pertanyaan menjawab pertanyaan tentang apakah ada pengaruh komentar guru terhadap keterampilan menulis siswa kelas sebelas dari Sekolah Menengah Salafiyah Islam Tungulangin Sidoarjo. Peneliti menggunakan metode kualitatif dan deskriptif. adapun metode pengumpulan data dengan cara observasi, wawancara dan dokumen. Penelitian ini disajikan dalam bentuk laporan dan uraian, kemudian disusun dalam bentuk hasil penelitian deskriptif dalam bentuk analisis interaktif. Adapun hasil analisis data dalam penelitian ini adalah, bahwa komentar guru dengan coretan dalam bentuk simbol tulisankomentar justifikasi, dan komentar penguatan mempunyai dampak positif pada peningkatan keterampilan menulis siswa sebagaimana dibuktikan oleh lembar kerja siswa.

Kata Kunci: komentar guru; keterampilan menulis; 
اللغة هي ألفاظ يعبر بهاكل قوم عن مقاصدهم. وفي هذا البحث، يبحث الباحث عن اللغة العربية. كانت اللغة العربية هي لغة محمة ، لابد على كل مسلم أن يتعلمها لأن العبادة والقرءان تستخدمان باللغة العربية وكذلك

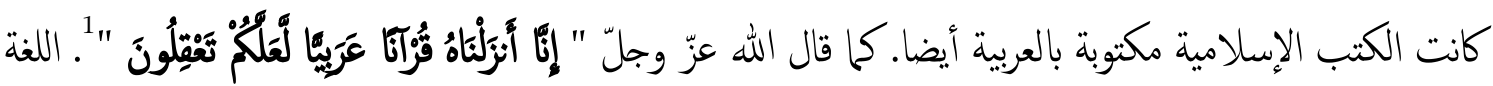
العربية هي الكلمات التي يعبر بها العرب عن أغراضهم, وقد وصلت إلينا من طريق النقل, وحفظها لنا القران الكريم والأحاديث الثريف, وما رواه الثقات من منثور العرب ومنظومهم. ُ ولها منزلة عالية كلغة القرآن الذي هو كلام الله المنزل إلى عبده وتكلم كل الأنيياء والمرسلين ولذلك تكون اللغة العربية كلغة الجنة. 3 إن اللغة العربية في الزمان قد سارت لغة رممية في العالم. وهذا شيء مجيب. إن اللغة العربية في المحيط التعليمي لهؤلاء الطلبة تعيش في صراع مريد وأعم مع اللغة الأجنبية, وتعنني من تداخل متواصل وهذا ما يزيد الموقف سوءا وحطرا ويبرر الخوف علي مستقبل اللغة العربية. إذن، تعليم اللغة العربية يحتاج اهتماما شديدا في تعلمها من المدرسة الإبتدائية حتى الجامعة أما حكومية كانت أو أهلية لإنتشارها وتدريسها. وهذا ينتسب بمرحلة القدرة وتطور التلاميذ.

في هذا البحث، يستخدم الباحث محارة الكنابة. الكنابة كنشاط اللغة هو الأنشطة التي تتطلب القدرة على الإنتاج أو التعبير عن لغة إلى الطرف الأخر. والكنابة هي حهارة من المهارات اللغوية التي كانت يتعلمها الطلاب بعد الاستماع والقراءة والكلام. كانت ظاهرة تحدث حاليا في تعليم الكنابة في المدارس بشكل عام أظهرت على سوء نتاجُ الكنابة للطلاب. (1) هناك انخفاض اهتمام الطلاب، (2) عدم وجود تعود إلى تقاليد الكنابة أسباب الطلاب طغت عند الحصول على هذه المهمة لكنابة أو تأليف، (3) بعض الطلاب في حاجة إلى وقت طويل ليخرج مافي الذهن لوضع معا في شكل مكتوب،(4) و الطريقة الدقيقة التي يستخمها المعلم في التعليم ، وغير ذلك . البًا، الطريقة التي يستخدها المعلم في شكل محاضرات والسؤال والجواب ، يتصرف المعلم كمخبر يلعب دورًا مهيمًا جدًا ، وغالبًا ما يؤدي

$$
\text { 1البقأن الكركيه، سورة يوسف } 4 .
$$

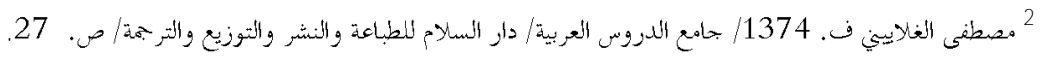

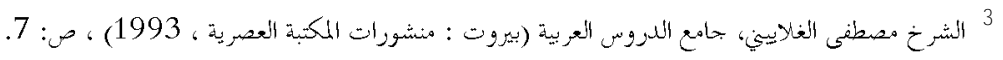

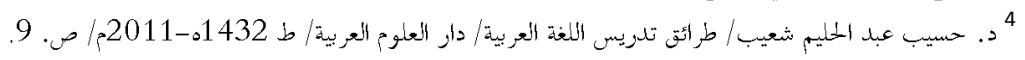

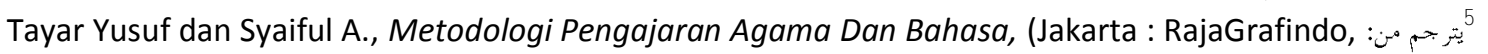

1995) hal 190. 
التفاعل الذي يحدث في التعليم إلى تشبع الطلاب ، بحيث يكون المحاس أو الحافز لدى الطلاب منخفضًا. هذا يؤثر بشكل كبير على نناجُ تعلم الطلاب ويؤدي إلى انخفاض التحصيل العلمي في تعليم اللغة العربية. بحيث تكون هناك تعليقات المعلم كنشاط لتوفير المعلومات التي تم الحصول عليها من الاختبارات أو أدوات القياس الأخرى لتحسين أو ترقية نتائُ تعلم الطلاب. في هذه المشكلة السابقة ، كما عرف الباحث في المدرسة السلفية الثانوية الإسلامية تانجولانجين سيدوارجو ، خصوصا في الفصل الحادي عشر " أ ".

استنادا إلى المشكلة السابقة التي وصفها الباحث، فيستخدم موضوع البحث عن تأثير تعليقات المعلم نحو محارة الككابة لطلاب الفصل الحادي عشر بالمدرسة السلفية الثانوية الإسلامية تانجولانجين سيدوارجو. الدرسة النظرية

\section{مفهوم التعليقات}

وفقال Ad. Rooijakkers الذي تربمه ج. هندريتو سوسادي في كتابه "الندريس بنجاح ، تعليات اللتخطيط وتعليم التدريس" بما يلي: النعليقات هو طلب المعلومات عن مدى فهم التعليم للطلاب التي تم تعلمها. بالإضافة إلى ذلك ، يتم إعطاء الطلاب الفرصة لفحص أنفسهم حتى أن يفهوا المواد ، حتى أن يتمنوا من إكمال

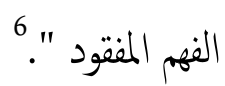

بينا وفقًا ل Slameto ، فإن التعليقات هو المعلومات المقدمة للطلاب عن الترقية في تحقيق أهداف

التعليم. ويتم تفسير التعليقات على أنها إخبار الطلاب بنتائكم في الإختبار الذي يقومون به بعد التعلم.7 يككن

إعطاء ملاحظات للطلاب للتغلب على صعوبات التعلم أو لتحسين إنجازاته. قال M.A ، Nasution أنه يجتاج المعلم على التعليقات في عملية التعليم والتعلم لتحقيق إتقان التعليم للطلاب. من البيان السابق ، أن التعليقات ترتبط ارتباطًا وثيقًا بأننطة التعليم والتعلم السابقة التي يتم تقييها بواسطة أداة التقييم. تقدم ننائُ التقييم معلومات حول مدى إتقان الطلاب للمواد المقدم في عملية التعليم والتعلم. Ad Rooijakkers, Mengajar Dengan Sukses, ( Jakarta: PT. Gramedia, 1986), h.11. Slameto, Evaluasi Pendidikan, (Jakarta: Rineka Cipta, 2002), h.190. 7 Nasution, M.A. Berbagai Pendekatan dalam Proses Belajar dan Mengajar, (Jakarta: Bumi يتر بن 8 Aksara, 1992), Cet.V, h.53. 
وفقا لتاريجان لحل خطاء الكتابة، يكن استخدام نوعين من: التصحيح المباشر و التصحيح غير مباشر. يستخدم المعلم التصحيح غير مباشر باعتبار الطلاب أقل قدرة على تصحيح أخطاء الكنابة. وكذلك يستطع المعلم لتحسين من الأخطاء في كنابة الطلاب. يككن المعلم أيضا يستخدم التصحيح المباشر باعتبار بهذا التعليقات يستطيع الطلاب أن يعرف الأخطاء في أوراق العمل بالشخبطة التي يعطها المعلم و يستطيع الطلاب لتحسين من الأخطاء. وجود التصحيح المباشر و غير مباثر في عالم المدرسة، وبالخصوص في همارة الكتابة هم جدا لتحسين قدرة الطلاب. و يستطيع الطلاب لتصحيح الأخطاء فى أوراق العمل التي تم المعلم التصحيح فيها. في هذا البحث، رأى الباحث أن مهارات كتابة الطلاب ليست صحيحة بعد ويجب أن يكون هناك الكثير من المبررات لذلك يحتاج المعلم إلى إجراء تصحيحات على كتابة الطلاب التي يكون الأخطأ فها، حتى أن يستخدم المعلم التصحيح غير مباشر لترقية محارة الكنابة للطلاب. التصحيح غير المباشر هو تصحيح أو تصحيح أو امتحان من خلال توفير رموز في شكل تبرير وتعليقات مبررات لتقييم ننابُ أوراق عمل الطلاب التي أجراها المعلم لتقييم نتائُ كتابة الطلاب. في هذه الحالة ، يفترض الباحث أيضًا أن تقنية التصحيح غير المباشر مناسبة لتعلم كتابة اللغة العربية هو 1) يمكن للطلاب تحسين الكنابة العربية والفهم من خلال تطبيق تصحيح غير مباشر. 2) يمكن للطلاب على الفور في معرفة موقع الأخطاء في كنابة اللغة العربية الصحيحة. 3) يككن للطلاب على الفور في معرفة الإجابات الصحيحة التي أعطى المعلم التعليقات من خلال تقنيات التصحيح غير المباشر.

\section{علامات التصحيح}

قبل إرسال ننائُ ورقة العمل إلى المعلم ، يجب الطلاب على قراءة كل ورقة العمل مرة أخرى لمعرفة ما إذا لم تكن هناك أخطاء في حل المشكلات من طريقة الكتابة والإملاء وترتيب الجمل والقواعد. يمكن وضع علامات التصحيح مباثرة في النص أو على حافة ورقة العمل الموازية للسطر المعني. يجب وضع كل علامة تحسن 
في الصف على التوالي على حافة الورقة ؛ إذا لزم الأمر ، كل واحدة مفصولة بعلامة قطرية أو شرطة مائلة. 10 يتوافق هذا مع الأبحاث التي أجراها ساتي و سيف الدين الذين قالوا إن تطبيق تصحيحات غبر مباشرة مع بعض علامات التصحيح يمكن أن يحسن جودة كتابة الطلاب ويفضل الطلاب التصحيحات غير المباشرة لأهه يفهمون بشكل أفضل. وظيفة التعليقات

كانت ثلاثة وظائف الرئسية في التعليقات. وهي وظيفة الإعلامية والتحفيزية والمجتمية. 'أولا: وظيفة الإعلامية، يمكن أن توضح نتائُ الاختبار مدى إتقان الطلاب للمواد التي يتعلمونها في عملية التعليم والتعلم بناءً على النتاجُ التي تح اختبارها وفقًا لمعايير معينة تم تحديدها مسبقًا. راجعا على هذه المعلومات ، يكنن سعت التعليقات في شكل الإثراء أو التحسين. حيث يمكن للمعلم تقديم مدخلات أو نصيحة لحفاظ أو تحسين النتاجُ التي حققها الطلاب. ثانيا: وظيفة التحفيزيةـ يعد نتاجُ الاختبار حافزًا للطلاب على النعلم ، لأن هناك بعض المعلمين الذين يستخدمون نتاجُ الاختبار كسلاح لمعاقبة الطلاب أكثر من كنهم قوة بناءة لتعزيز الطلاب وتطويرهم. سيكون الطلاب متحمسين للتعلم إذا كانوا يريدون موابجة الاختبار ، لأنه إذا لم تكن نتأج الاختبار جيدة ، فسيخجل الطلاب من حصولم على العقاب من المعلم ، لذلك يكون الطلاب متحمسين للتعلم. ثالثا: وظيفة المجتمعية، ينقل المعلم نتاجُ الهخبار للطلاب ، ويناقش مع الطلاب الجهود المبذولة لتحسينها أو تحسينها. وبالتالي ، من خلال تعليقات الطلاب لمعرفة نقاط الضعف أنفسهم ومع المعلم رد فعل على هذه النتاجُ. مؤاشرات الثعليقات

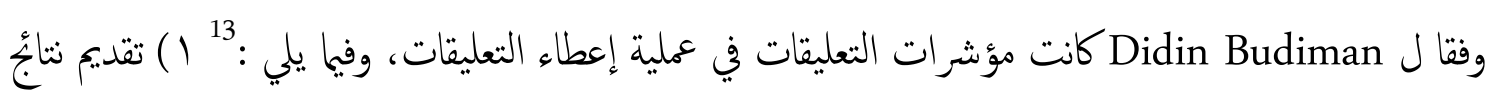
التعلم للطلا، r) الانساق في إعطاء التعليقات للطلاب، r) التواصل بين المعلم والطلاب في التعلم. أشكال من الثعليقات

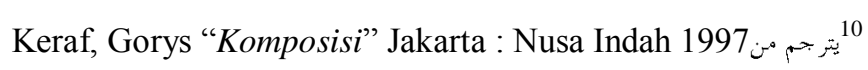
Santi Pratiwi Tri Utami dan Ahmad Syaifudin" penerapan teknik koreksi tidak langsung untuk يتر من من من " meminimalkan kesalahan berbahasa dalam menyusun karya ilmiah pada mahasiswa non jurusan bahasa" (Jurnal-UNNES 2012) : Jakarta, 1991),h.149. Grasindo(Suke Silverius, Evaluasi Hasil Belajar dan Umpan Balik, : 12 Didin Budiman, Bahan ajar pedagogi Olah Raga, (Bandung: FPOK UPI, 2011) 13 13 جمث من: 
هناك أشكال من التعليقات التي يتم شرحا مصادر مختلفة، وفيا يلي : أولا: التأيد (Reinforcement) وفقا ل Apruebo ، التعليقات هو التأكيد، يعني إعطاء التأيد للأحداث أو الأنشطة التي تح تنفيذها بجيث

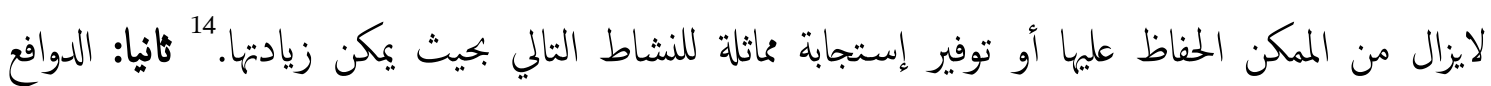
(Motivation) (الدوافح هو هم جدا بجيث يكون لدي الطلاب حهاس و شفف كير للمشاركة في عملية التعلم. يجعل التعليقات طلابا حاسا لتحسين أو ترقية إنجازاتهم. لذلك يجب أن يتح التعليقات في إطار إجابي حتى لايكون هناك انخفاض في الدوافع. ${ }^{15}$ ثالثا: العقاب (Hukuman)، وفقا ل Didin Budiman أن سلوك الطلاب لا يتوافق مع توقعات المعلم، يجب أن تكون لمم عقوبة. و يتم ذلك على أمل ألا يحدث السلوك و لا يتكرر، ويؤدي إلى التصرف المتوافق مع توقعات المعلم. العقاب هو أكثر من حكم سيء مع المعاملة السلبية. على سبيل المثال " الإجابة الخاطئة " ولكن يمكن استبدالها بمعاجلة أو بعبارة إجابية " الإجابة غير صحيحة، حاول مرة

\section{معارة الكنابة}

فأمّا محارة الكتابة فهي قدرة الفرد في تعبير التفكير من اختباره و تمرينه في الكنابة المفهومة لنفسه ولنفس الأخر. ${ }^{17}$ تعمّ محارة الكتابة أصعب من المهارات الأخرى، لأها تحتاج العناصر اللّفوية و غير اللّفوية لتحصيل الكتابة. 18 وهي المهارة الثانوية من أربع المهارات اللغوية (همارة الاستحاع، محارة الكلام، مهارة القراءة، ومحارة الكنابة). الكنابة إحدى وسائل الاتصال اللغوي بين الأفراد لا محدود بوقت أو بمكان.

\section{طريقة البحث}

طريقة هذا البحث التي يستخدما الباحث هي الطريقة الكيفية.وصفته هو بحث المكتبة والدراسة الميدانية.

وأما جنس هذا البحث فهو كيفية وصفية. يستخدما الباحث لنظر تأثير تعليقات المعلم نحو عحارة الكنابة لطلاب

Didin Budiman, Bahan Ajar Pedagogi Olah Raga,(Bandung: FPOK UPI, 2009) 14

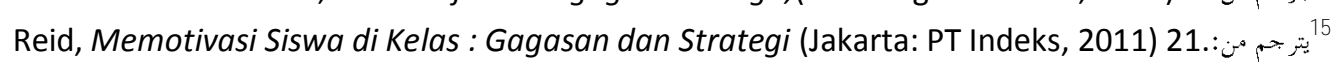

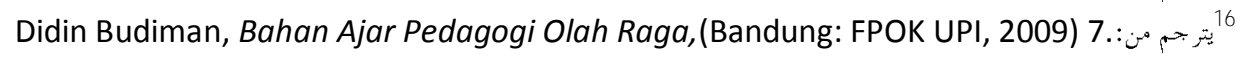
Muhammad Thohir, Pengantar Psikolinguistik, (Surabaya: UINSA PRESS, 2014), C1, hal. 142- 17

Mulyono, Kumpulan Karangan Tersebar, (Jakarta: Gramedia, 1999), hal. 143 
الفصل الحادي عشر بالمدرسة السلفية الثانوية الإسلامية تانجولانجين سيدوارجو. البيانات هي كل ما يحتاج من هذ البحث وقد يستعمل الباحث طريقة كثيرة موافقة هذ البحث كما يلي : الملاحظة (Observasi) والمقابلة

(Wawancara)

\section{تصديق البيانات (Uji Keabsahan Data)}

تصديق البيانات أو يسمى بالتثليث ينال من مصادر متنوعة بطرق وفي أوقات مختلفة. الهدف منه لمعرفة صدق البيانات وثنتها. ${ }^{19}$ ويقام تصديق البيانات عن تعليقات المعلم نحو مهارة الكتابة لطلاب الفصل الحادي عشر بالمدرسة السلفية الثانوية الإسلامية تانجولانجين سيدوارجو، كما يلي :

تثليث المصدر (Triangulasi Sumber)

تنفذ طريقة تثليث المصدر بتصديق البيانات، ويستخدم الباحث المصادر. تسمى بالبيانات التصديقية إذا

$$
\text { كان المصدر ثثتا، أو لا يوجد الاختلاف بين مصدر واحد مع مصادر أخرى. }
$$
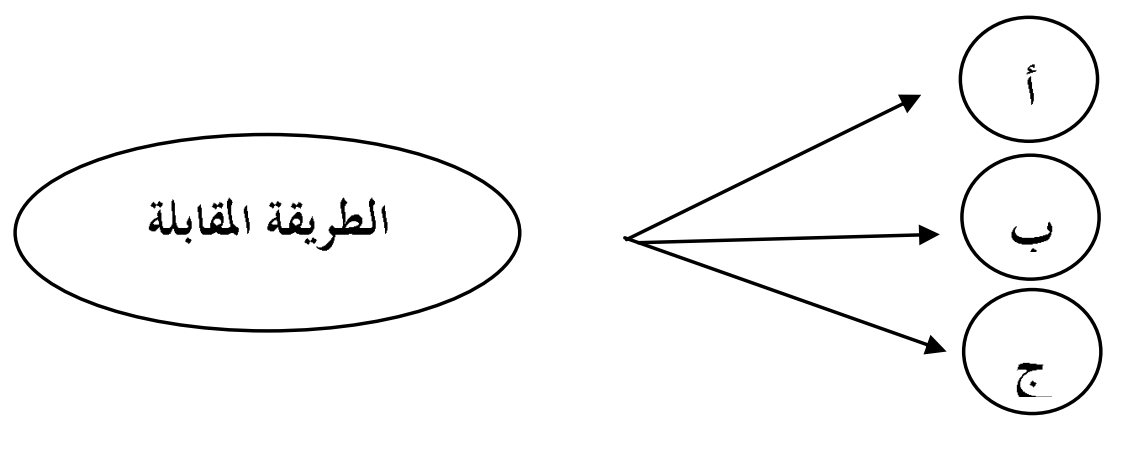

الصورة 1.1 عن ثلثيث المصدر

تثليث التقنية (Triangulasi Teknik)

يقوم تثليث التقنية به طريقة تصديق البيانات إلى مصادر متساويا، ولكن بتقنية مختلفة. على سبيل المثال : البيانات المكتسبة بطريقة المقابلة، تصدق بطريقة الملاحظة والوثائت. إداكان البيانات مختلفة، يجري الباحث المناقشة مع مصادر البيانات أو فاعل البحث الأخرى الذين يستطيعون أن يعطى البيانات الصحيحة.

Sugiyono, Metode Penelitian Pendidikan : Pendekatan Kualitatif, Kuantitatif, dan R \& D, hlm : ئر من من 19 


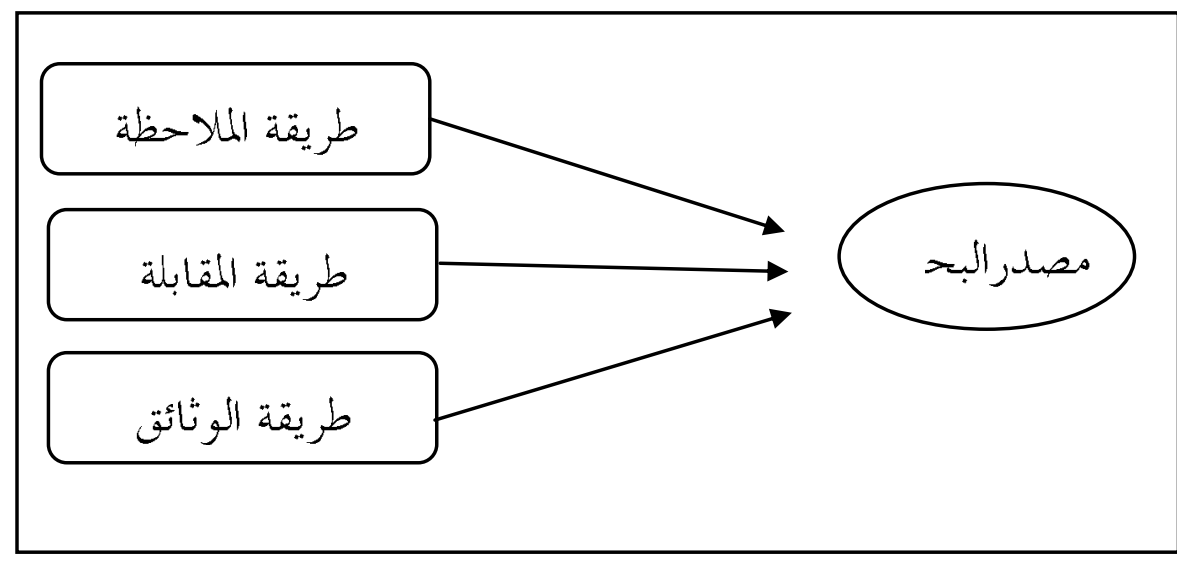

الصورة 1.2 عن تلثيث الثقنية

تثليث الزمان (Triangulasi Waktu)

تقوم هذه الطريقة بتصديق البيانات بوسيلة طريقة المقابلة والملاحظة و الوثائق في الوقت و والموضع المختلفة، تنفيذ تثليث الزمان تكرارا لتحديد صدق البيانات. تمليل البيانات

وأما تحليل البيانات في هذا البحث العلمي فهو التحليل التفاعلي (Analisis interaktif) وفقا لميلز و هوبيرمان (Mules)

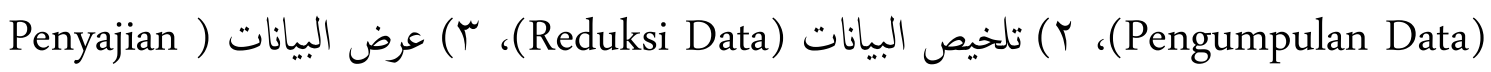
(Penarikan Kesimpulan) (Data

\section{البحث}

في مهارة الكتابة هناك ثلاثة مؤانرات لقياس القدرة على كتابة اللغة العربية بشكل صيح، بما في ذلك تحويل الجملة وتكوين الجملة وكتابة الفقرة. يأخذ الباحث 15 على أوراق عمل الطلاب من الفصل الحادي عشر بـ بالمدرسة السلفية الثانوية الإسلامية تانجولانجين سيدوارجو لأخذ العينة من هذا البحث. الأستاذ سيف الهدى الذي يدرس اللغة العربية، هو يعطي التدريبات للطلاب في يوم الثلاثاء التاريخ 30 أبريل 2019 لمعرفة قدرة الطلاب في فهم المواد الذي بين المعلم اليوم. يجد الباحث الأخطاء المتنوعة من أوراق عمل الطلاب و تعليقات المعلم المتنوع فهيا. الشرح على النحو التالي: 
الغرض من تحويل الجملة لندريب الطلاب في تطوير الفقرة و تطبيق القواعد. المؤاشرات من تحويل الجملة هي دقة تطبيق القواعد و ضبط الفاعل مع الفعل. الحصول على البيانات من أوراق عمل الطلاب. محفوظ بحرالدين

كانت الأخطاء من تحويل الجملة في ورقة عمل محفوظ بحرالدين التي تُكن في دقة تطبيق القواعد و يعطي المعلم التعليقات عليها بالشخبطة في شكل رموز الكتابة (الشرطة السفلية أو الدوائر أو الصلبان) وتعليقات التبرير. كمثل في لفظ "يستيقون" الذي يصححه المعلم بلفظ "يستيقظ"، ولفظ "يذهبوا" الذي يصحه المعلم بلفظ "يذهبون"، ولفظ "تستيقظن" الذي يصحهه المعلم بلفظ "تستيقظ". فائزالدين

كانت الأخطاء من تحويل الجملة في ورقة عمل فائزالدين التي تمكن في دقة تطبيق القواعد و يعطي المعلم التعليقات عليها بالشخبطة في شكل رموز الكنابة (الثرطة السفلية أو الدوائر أو الصلبان) وتعليقات التبرير. كثل في لفظ "يستيقوا" الذي يصحهه المعلم بلفظ "يستيق"، ولفظ "يذهبوا" الذي يصحهه المعلم بلفظ "يذهبون".

رئيسمان

كانت الأخطاء من تحويل الجملة في ورقة عمل رئيسان التي تمكن في دقة تطبيق القواعد و يعطي المعلم التعليقات عليها بالشخبطة في شكل رموز الكنابة (الشرطة السفلية أو الدوائر أو الصلبان) وتعليقات التبرير. كثل في لفظ "تستيقظو" الذي يصحهه المعلم بلفظ "يستيقظ"، ولفظ "يذهبوا" الذي يصحهه المعلم بلفظ "يذهبون"، ولفظ "تستيقظن" الذي يصحهه المعلم بلفظ "تستيقظ"، ولفظ "يذهبن" الذي يصحهه المعلم بلفظ

$$
\text { "تذهبن". }
$$

كانت الأخطاء من تحويل الجملة في ورقة عمل رضاء ابن عمر التي تمكن في دقة تطبيق القواعد و يعطي

المعلم التعليقات عليها بالشخبطة في شكل رموز الكنابة (الشرطة السفلية أو الدوائر أو الصلبان) وتعليقات 
التبرير. كمثل في لفظ "يستيقظون" الذي يصحهه المعلم بلفظ "يستيقظ"، ولفظ "يذهب" الذي يصحه المعلم بلفظ "يذهبون"، ولفظ "تذهب" الذي يصححه المعلم بلفظ "تذهبن".

$$
\text { ديماس أسرافي }
$$

كانت الأخطاء من تحويل الجملة في ورقة عمل ديماس أسرافي التي تمكن في دقة تطبيق القواعد و يعطي المعلم التعليقات عليها بالشخبطة في شكل رموز الكنابة (الشرطة السفلية أو الدوائر أو الصلبان) وتعليقات التبرير. كمثل في لفظ "يستيقظوا" الذي يصححه المعلم بلفظ "يستيقظ"، ولفظ "يذهبوا" الذي يصحه المعلم بلفظ "يذهبون"، ولفظ "يستيقظن" الذي يصحه المعلم بلفظ "تستيقظ"، ولفظ "يذهبن" الذي يصحهه المعلم

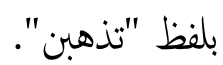
حسبي وافي كانت الأخطاء من تحويل الجملة في ورقة عمل حسبي وافي التي تمكن في دقة تطبيق القواعد و يعطي المعلم التعليقات عليها بالشخبطة في شكل رموز الكنابة (الشرطة السفلية أو الدوائر أو الصلبان) وتعليقات التبرير. كمثل في لفظ "يستيقظوا" الذي يصححه المعلم بلفظ "يستيقظ"، ولفظ "يذهبوا" الذي يصحه المعلم بلفظ "يذهبون"، ولفظ "تستيقظن" الذي يصححه المعلم بلفظ "تستيقظ". نصير الدين كانت الأخطاء من تحويل الجملة في ورقة عمل نصيرالدين التي تمكن في دقة تطبيق القواعد و يعطي المعلم التعليقات عليها بالشخبطة في شكل رموز الكنابة (الشرطة السفلية أو الدوائر أو الصلبان) وتعليقات التبرير. كثل في لفظ "يستيقظون" الذي يصححه المعلم بلفظ "يستيق"،ولفظ "تذهب" الذي يصححه المعلم بلفظ "نذهبن". رحمة خير

كانت الأخطاء من تحويل الجملة في ورقة عمل رمة خير التي تمكن في دقة تطبيق القواعد و يعطي المعلم التعليقات عليها بالشخبطة في شكل رموز الكنابة (الشرطة السفلية أو الدوائر أو الصلبان) وتعليقات التبرير. كثثل في لفظ "يستيظوا" الذي يصححه المعلم بلفظ "يستيق"، ولفظ "يذهبوا" الذي يصححه المعلم بلفظ 
"يذهبون"، ولفظ "يستيقظن" الذي يصحه المعلم بلفظ "تستيقظ"، ولفظ "يذهبن" الذي يصحهه المعلم بلفظ

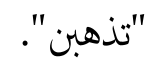
محمد صاخ

كانت الأخطاء من تحويل الجملة في ورقة عمل محمد صالح التي تمكن في دقة تطبيق القواعد و يعطي المعلم التعليقات عليها بالشخبطة في شكل رموز الكنابة (الثرطة السفلية أو الدوائر أو الصلبان) وتعليقات التبرير. كثثل في لفظ "يستيقظوا" الذي يصحه المعلم بلفظ "يستيقظ"، ولفظ "يذهب" الذي يصحه المعلم بلفظ "يذهبون"، ولفظ "تذهب" الذي يصححه المعلم بلفظ "يذهبن". خير الأنام

كانت الأخطاء من تحويل الجملة في ورقة عمل خير الأنام التي تمكن في دقة تطبيق القواعد و يعطي المعلم التعليقات عليها بالشخبطة في شكل رموز الكنابة (الشرطة السفلية أو الدوائر أو الصلبان) وتعليقات التبرير. كثل في لفظ "يستيقظ" الذي يصحهه المعلم بلفظ "تستيقظ"، ولفظ "يستيقظوا" الذي يصحهه المعلم بلفظ "يستقظ"، ولفظ "يذهب" الذي يصحهه المعلم بلفظ "يذهبون"، ولفظ "تستيقظن" الذي يصحهه المعلم بلفظ "تستيقظ". ميكو أدي فراتاما كانت الأخطاء من تحويل الجملة في ورقة عمل ميكو أدي فراتاما التي تمكن في دقة تطبيق القواعد و يعطي المعلم التعليقات عليها بالشخبطة في شكل رموز الكنابة (الشرطة السفلية أو الدوائر أو الصلبان) وتعليقات التبرير. كثثل في لفظ "يستيقظوا" الذي يصحه المعلم بلفظ "يستيقظ"، ولفظ "تذهب" الذي يصحهه المعلم

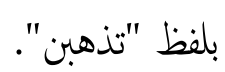
ألفي شهر

كانت الأخطاء من ورقة عمل ألفي شهر التي تمكن في دقة تطبيق القواعد و يعطي المعلم التعليقات عليها بالشخبطة في شكل رموز الكنابة (الشرطة السفلية أو الدوائر أو الصلبان) وتعليقات التبرير. كثل في لفظ "يستيقظون" الذي يصححه المعلم بلفظ "يستيقظ". 
كانت الأخطاء من تخويل الجملة في ورقة عمل سيد عبد الرحمن التي تمكن في دقة تطبيق القواعد و يعطي المعلم التعليقات علها بالشخبطة في شكل رموز الكنابة (الشرطة السفلية أو الدوائر أو الصلبان) وتعليقات التبرير. كثل في لفظ "يستيقظوا" الذي يصحهه المعلم بلفظ "يستيقظ"، ولفظ "تذهبوا" الذي يصحه المعلم بلفظ "يذهبون"، ولفظ "يذهبن" الذي يصححه المعلم بلفظ "تذهبن". أوغكي أدي سافوترا

كانت الأخطاء من تحويل الجملة في ورقة عمل أدي سافوترا التي تمكن في دقة تطبيق القواعد و يعطي المعلم التعليقات عليها بالشخبطة في شكل رموز الكنابة (الشرطة السفلية أو الدوائر أو الصلبان) وتعليقات التبرير. كمثل في لفظ "تذهب" الذي يصحه المعلم بلفظ "يذهبون"، ولفظ "تذهب" الذي يصحهه المعلم بلفظ

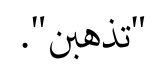

$$
\text { أيروين سافوترا }
$$

كانت الأخطاء من تحويل الجملة في ورقة عمل ديماس أسرافي التي تمكن في دقة تطبيق القواعد و يعطي المعلم التعليقات عليها بالشخبطة في شكل رموز الكنابة (الشرطة السفلية أو الدوائر أو الصلبان) وتعليقات التبرير. كمثل في لفظ "تذهبون" الذي يصحهه المعلم بلفظ "تذهبن". تكوين الجملة

في تكوين الجملة، يتم تدريب الطلاب لجعل الجملة المفيدة بالمفردات المعينة. المؤاشرات من تكوين الجملة هي

الدقة في اختيار المفردات و دقة تطبيق القواعد و دقة المحتوى. الحصول على البيانات من أوراق عمل الطلاب

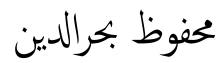


كان الخطاء من تكوين الجملة في ورقة عمل محفوظ بحرالدين الذي يمكن في دقة اختيار المفردات و يعطي المعلم التعليقات عليها بالشخبطة في شكل رموز الكنابة (الشرطة السفلية أو الدوائر أو الصلبان) وتعليقات التبرير. كثل في لفظ "قبل" الذي يصححه المعلم بلفظ "استسلم". فائزالدين

كان الخطاء من تكوين الجملة في ورقة عمل فائزالدين الذي يككن في دقة اختيار المفردات و يعطي المعلم التعليقات عليها بالشخبطة في شكل رموز الكتابة (الشرطة السفلية أو الدوائر أو الصلبان) وتعليقات التبرير. كثل في لفظ "ماض" الذي يصححه المعلم بكتابة "هذه الجملة صحيح في مجال النحو بل لا يناسب في مجال الدلالة".

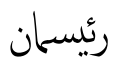
كان الخطاء من تكوين الجملة في ورقة عمل رئيسان الذي يككن في دقة اختيار المفردات و يعطي المعلم التعليقات عليها بالشخبطة في شكل رموز الكنابة (الثرطة السفلية أو الدوائر أو الصلبان) وتعليقات التبرير. كثل في لفظ "حفل" الذي يصححه المعلم بلفظ "حفلة".

$$
\text { رضاء ابن عمر }
$$

عدم الخطاء في ورقة عمل رضاء ابن عمر بجيث مافي التعليقات الذي يعطيه المعلم على ورقة عمله.

$$
\text { ديماس أسرافي }
$$

عدم الخطاء في ورقة عمل ديماس أسرافي بجيث مافي التعليقات الذي يعطيه المعلم على ورقة عمله.

$$
\text { حسبي وافي }
$$

كان الخطاء من تكوين الجملة في ورقة عمل حسبي وافي الذي يككن في دقة اختيار المفردات و يعطي المعلم التعليقات عليها بالشخبطة في شكل رموز الكنابة (الشرطة السفلية أو الدوائر أو الصلبان) وتعليقات التبرير. كثل في لفظ "قبل" الذي يصححه المعلم بلفظ "استسلم". نصير الدين 
كان الخطاء من تكوين الجملة في ورقة عمل نصير الدين الذي يككن في دقة الحتوى و يعطي المعلم التعليقات عليها بالشخبطة في شكل رموز الكتابة (الشرطة السفلية أو الدوائر أو الصلبان). كثثل في لفظ "الأمطار" بينما يبين المعلم المواد عن نزول القرءان. رمة خير

كان الخطاء من تكوين الجملة في ورقة عمل رحمة الذي يمكن في دقة الحتوى و يعطي المعلم التعليقات عليها بالشخبطة في شكل رموز الكنابة (الشرطة السفلية أو الدوائر أو الصلبان). كثنل في لفظ "الأمطار" بينا يبين

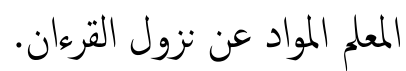
محمد صاخ كان الخطاء من تكوين الجملة في ورقة عمل محمد صالح الذي يكنن في دقة الحتوى و يعطي المعلم التعليقات عليها بالشخبطة في شكل رموز الكتابة (الشرطة السفلية أو الدوائر أو الصلبان). كثل في لفظ "المطار" بينا يبين

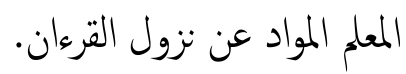
خير الأنام

كان الخطاء من تكوين الجملة في ورقة عمل خير الأنام الذي يكن في دقة تطبيق القواعد و يعطي المعلم التعليقات عليها بالشخبطة في شكل رموز الكنابة (الشرطة السفلية أو الدوائر أو الصلبان). كثل في لفظ "نزله" الضمير في هذه الكلمة غير واضح عن العودة إلى ما غير موجود. ميكو أدي فراتاما كان الخطاء من تكوين الجملة في ورقة عمل ميكو أدي فراتاما الذي يككن في دقة اختيار المفردات و يعطي المعلم التعليقات عليها بالشخبطة في شكل رموز الكنابة (الشرطة السفلية أو الدوائر أو الصلبان) وتعليقات التبرير. كمثل في لفظ "ماض" الذي يصحهه المعلم بكتابة "هذه الجملة صحيح في مجال النحو بل لا يناسب في

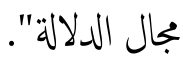
ألفي شهر عدم الخطاء في ورقة عمل ألفي شهر بجيث مافي التعليقات الذي يعطيه المعلم على ورقة عمله. 
عدم الخطاء في ورقة عمل سيد عبد الرحمن بحيث مافي النعليقات الذي يعطيه المعلم على ورقة عمله.

$$
\text { أوغنكي أدي سافوترا }
$$

عدم الخطاء في ورقة عمل أوغكي أدي سافوترا بجيث مافي التعليقات الذي يعطيه المعلم على ورقة عمله.

$$
\text { أيروين سافوترا }
$$

عدم الخطاء في ورقة عمل أيروين سافوترا بحيث مافي التعليقات الذي يعطيه المعلم على ورقة عمله.

في كتابة الفقرة، يتم تدريب الطلاب لجعل الإنشاء الحر عن الموضوع المعين. المؤاشرات من كتابة الفقرة هي الدقة في اختيار المفردات و دقة تطبيق القواعد و دقة المحتوى و الدقة في تأليف الجملة الئيسية و الداعمة. الحصول على البيانات من أوراق عمل الطلاب محفوظ بحرالدين

كانت الأخطاء من كتابة الفقرة في ورقة عمل محفوظ بحر الدين التي تمكن في دقة تطبيق القواعد و النقص في تأليف الجملة الرئيسية والداعمة و يعطي المعلم التعليقات عليها بالشخبطة في شكل رموز الكتابة (الشرطة السفلية أو الدوائر أو الصلبان) وتعليقات التبرير. كثثل في لفظ "مبكر" و تعليقات التبرير بكنابة "كثرة التكرار عن الكلة بل معناه مؤخر" و "على الأحسن : نزل الله القرءان إلى نبينا محمد في شهر رمضان يقع في التاريخ سبعة عشر، وسمي ب :ليلة القدر". فائزالدين كانت الأخطاء من كنابة الفقرة في ورقة عمل فائزالدين التي تمكن في دقة اختيار المفردات و دقة تطبيق القواعد و النقص في تأليف الجملة الرئيسية والداعمة و يعطي المعلم التعليقات عليها بالشخبطة في شكل رموز الكنابة (الشرطة السفلية أو الدوائر أو الصلبان) وتعليقات النبرير. كثل في لفظ "أنا و صديقي أذهب" الذي يصححه المعلم بلفظ "نذهب" و لفظ "المسلمون يذهبون" و تعليقات التبرير بكتابة "لا أفهم عن المعنى من هذه 
الإنشاء بل سأبحث عن فعل و فاعل : 1- نذهب مع صديقي لأن في قاعدة العرب تفضل الفعل من الفاعل. 2يذهب المسلمون : الأحسن فعل مفرد في أول الكلمة".

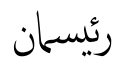

كانت الأخطاء من كتابة الفقرة في ورقة عمل رئيسان التي تمكن في دقة اختيار المفردات و دقة تطبيق القواعد و النقص في تأليف الجملة الرئيسية والداعمة و يعطي المعلم التعليقات عليها بالشخبطة في شكل رموز الكتابة (الشرطة السفلية أو الدوائر أو الصلبان) وتعليقات التبرير. كمثل في لفظ "يحفل" الذي يصحه المعلم بلفظ "يكتفل" و لفظ "بفراح" الذي يصحهه المعلم بلفظ "بفح". رضاء ابن عمر

عدم الخطاء في ورقة عمل رضاء ابن عمر بحيث مافي التعليقات الذي يعطيه المعلم على ورقة عمله.

$$
\text { ديماس أسرافي }
$$

كانت الأخطاء من كتابة الفقرة في ورقة عمل ديماس أسرافي التي تمكن في دقة تطبيق القواعد و النص في تأليف الجملة الرئيسية والداعمة و يعطي المعلم التعليقات عليها بالشخبطة في شكل رموز الكتابة (الشرطة السفلية أو الدوائر أو الصلبان) وتعليقات التبرير. كثل في لفظ "أنا مع صديقي يذهب" الذي يصحه المعلم بتعليقات التبرير بكتابة "ابداء بالفعل أولا". حسبي وافي كانت الأخطاء من كتابة الفقرة في ورقة عمل حسبي وافي التي تمكن في دقة اختيار المفردات و دقة تطبيق القواعد و النقص في تأليف الجملة الرئيسية والداعمة و يعطي المعلم التعليقات عليها بالشخبطة في شكل رموز الكتابة (الشرطة السفلية أو الدوائر أو الصلبان) وتعليقات التبرير. كثل في لفظ "مبكر" و لفظ "يحفل" الذي يصححه المعلم بلفظ "يحتفل" و تعليقات التبرير بكتابة "في قاعدة العرب تفضل فعل من الفاعل". من البيان السابق، الذي تم الحصول في يوم الثلاثاء التاريخ 30 أبريل 2019، يستنتج الباحث أن أوراق عمل الطلاب قبل أن يعطي المعلم التعليقات كانت الأخطاء في تحويل الجملة و تكوين الجملة و كتابة الفقرة. و يعطي المعلم التعليقات في أوراق عمل الطلاب بالشخبطة في شكل رموز الكنابة (الثرطة السفلية أو الدوائر أو 
الصلبان) وتعليقات التبرير بعد أن يعرف المعلم الأخطاء المتنوعة فها. بعد إعطاء التعليقات للمعلم، يرجي المعلم أن الطلاب يعرفون اللأخطاء و يقدرون الإجابات بشكل صحيح. وتعليقات المعلم في هذا البحث هو نشاط توفير المعلومات التي تم الحصول عليها من الاختبارات أو أدوات القياس الأخرى للطلاب لتحسين أو ترقية تحقيق نتائج تعلم الطلاب. التعليقات متنوع الذي يعطيه المعلم لطلاب الفصل الحادي عشر بالمدرسة السلفية الثانوية الإسلامية تانجولانجين سيدوارجو. مثل أعطاء الشخبطة في شكل رموز الكنابة ( الشرطة السفلية أو الدوائر أو الصلبان) وتعليقات الثبرير و تقديم التعزيز. التعليقات هم في عملية تعليم والتعلم. ليكون التعليقات الذي يعطيه المعلم ليساعد الطلاب لفهم درس اللغة العربية. وكذلك، هو الهدف من التعليقات الذي يقدمه المعلم و قادر على تحسين تحقيق نتابُج تعلم الطلاب. يعطي المعلم التعليقات المتنوع على أوراق عمل الطلاب لطلاب الفصل الحادي عشر بالمدرسة السلفية الثانوية الإسلامية تانجولانجين سيدوارجو بالشخبطة في شكل رموز الكتابة ( الشرطة السفلية أو الدوائر أو الصلبان) وتعليقات النبرير. على سبيل المثال يعطي الأستاذ سيف الهدى النعليقات على ورقة عمل حسبي وافي بكتابة "في قاعدة العرب تفضل فعل من الفاعل". يعطي الأستاذ مثل هذا التعليقات على ورقة عمل محمد صاح بكتابة "على الأحسن تفضل الفعل من الفاعل كما نظام في قاعدة العرب". يعطى هذه النعليقات ليعرف الطلاب عن الأخطاء حتى أنه يساعد الطلاب أن يعرفوا عن الأخطاء و يصحح على الجواب الخاطئ. ويتجلي ذلك بعد أن يجي الباحث المقابلة مع بعض الطلاب، بما في ذلك محفوظ بحر الدين الذي يقوله :"التعليقات مفيد جدا، لأنه يكن أن أفهم تخطيط الخطاء و يساعد في الإجابة بشكل صحيح". بسبب إعطاء تعليقات المعلم بالشخبطة في شكل رموز الكتابة ( الثرطة السفلية أو الدوائر أو الصلبان) وتعليقات التبرير على أوراق عمل الطلاب التي يجد الأخطاء فيها مثل إعطاء الشخبطة في شكل رموز الكتابة ( الشرطة السفلية أو الدوائر أو الصلبان) وتعليقات التبرير على الجملة التي يصححها. وكذلك، يساعد الطلاب ان يعرفوا و يفهوا عن الإجابات الصحيحة. 


$$
\begin{aligned}
& \text { التعليقات التي قدما معلم اللغة العربة لطلاب الفصل الحادي عشر بالمدرسة السلفية الثانوية الإسلامية } \\
& \text { تانجولانجين سيدوارجو متنوعة، بما في ذلك إعطاء الشخبطة و تعليقات التبرير على أوراق عمل كتابة الطلاب } \\
& \text { حيث توجد أخطاء. بلإضافة إلى ذلك، يوفر المعلم تعزيزا في شكل مناقشة مع الطلاب فيا يتعلق ببعض المواد } \\
& \text { التي لم يفهما بعض الطلاب و إعطاء الدافع للطلاب. }
\end{aligned}
$$

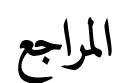

Al-Ghulâyaini. Mușțafâ. 13. Jâmi' al-durûs al-'Arabiyah. Beirut: Mansyûrât alMaktabah al-'Așriyah.

Al-Ghulâyaini. Mușțafâ. Al-Mu'jam al-Wâsiț fî al-Lughah al-'Arabiyah al-Mu'așirah. Beirut: Dâr al-Masyruq.

Arikunto, Suharsimi. 1996. Metodologi Penelitian. (Jakarta: Bulan Bintang).

Budiman, Didin. 2009. Bahan Ajar Pedagogi Olah Raga. (Bandung: FPOK UPI).

Dayat. 2015. Efektivitas Direct Correction dalam meningkatkan kemampuan menulis mahasiswa IKIP PGRI Pontianak. (IKIP PGRI Pontianak)

Hadi, Sutrisno. 1989. Metodologi Penelitian. (Jakarta : Andi Offset). Cet. 18.

Keraf, Gorys. 1997. Komposisi (Jakarta : Nusa Indah)

Mordalis. 1999. Metode Penelitian Suatu Pendekatan Proposal. (Jakarta: Bum Aksara).

Mulyono. 1999. Kumpulan Karangan Tersebar. (Jakarta: Gramedia).

Nasution, M.A. 1992. Berbagai Pendekatan dalam Proses Belajar dan Mengajar. (Jakarta: Bumi Aksara).Cet.V.

Reid. 2011. Memotivasi Siswa di Kelas: Gagasan dan Strategi. (Jakarta: PT Indeks).

Rooijakkers, Ad. 1986. Mengajar Dengan Sukses. ( Jakarta: PT. Gramedia).

Santi Pratiwi Tri Utami dan Ahmad Syaifudin. 2012. Penerapan Teknik Koreksi

Tidak Langsung Untuk Meminimalkan Kesalahan Berbahasa Dalam Menyusun Karya Ilmiah Pada Mahasiswa Non Jurusan Bahasa. (UNNES)

Silverius, Suke. 1991 Evaluasi Hasil Belajar dan Umpan Balik. (Grasindo : Jakarta).

Slameto. 2002. Evaluasi Pendidikan. (Jakarta: Rineka Cipta).

Sugiyono. 2003. Metode Penelitian Pendidikan Pendekatan Kuantitatif, Kualitatif, dan R\&D. (Bandung: CV. Alfabeta). 
Syuaib. Hasîb 'Abd al-Halîm. 1432H. Târaiq Tadrîs al-Lughah al-'Arabiyah. Dâr al'Ulûm al-'Arabiyah.

Thohir, Muhammad. 2014. Pengantar Psikolinguistik. ( Surabaya: UINSA PRESS).

Yusuf, Tayar dan Syaiful A.. 1995. Metodologi Pengajaran Agama Dan Bahasa. (Jakarta : RajaGrafindo). 